DOI:

UDC 330.4:664

H. Karimov, candidate of Economic Sciences (Ph.D), associate professor, gkarimov@ukr.net

K. Zvonarova, postgraduate student, t4908802@gmail.com

Dniprovsk State Technical University, Kamianske

\title{
MODELING OF THE FOOD INDUSTRY DEPENDENCE FROM RAW MATERIAL BASE
}

Numerous working of livestock and agricultural processing industry production. The analytical dependence of indicators of activity of the food industry on the volume crops has been carried out, which forms the raw material base of the enterprises of the food and of production of the main types of products of the agrarian sector of the food complex of the region is obtained. The regression model of dependence of the food industry on the raw material base has been constructed and evaluated.

Keywords: food industry; raw material base; livestock; plant growing; model.

Виконано чисельну обробку обсягів виробництва продукиії тваринництва та сільськогосподарських культур, що складає сировинну базу підприємств харчової та переробної промисловості. Отримано аналітичну залежність показників діяльності харчової промисловості від обсягу випуску основних видів продукиії аграрного сектору продовольчого комплексу регіону. Побудовано та оиінено регресійну модель залежності харчової промисловості від сировинної бази.

Ключові слова: харчова промисловість; сировинна база; тваринництво; рослинництво; модель.

\section{Problem Statement}

In modern conditions is greatly enhanced by the orientation activity of the food complex the country's on comprehensive and complete satisfaction of the needs of the population in inexpensive and high-quality foods. Therefore, priority becomes the problem of effective functioning and further development of food industry, its industries and productions [1]. In turn, the main source of raw materials for the food industry is the production of agricultural sector (stock - breeding and crops - growing) within the region.

\section{Analysis of recent researches and publications}

These issues dedicated to the works of many domestic and foreign scientists, who investigated problems of development of food complex, in particular, O. Alimov, P. Borschivsky, L. Deineko, Y. Izard, V. Kistanov, A. Lisetsky, N. Revutska, P. Sabluk, A. Palarchuk, O. Onyshchenko, Y. Fehyna, P. Heine and others [1-3]. But, despite the sufficiently complete description of the problem, some issues of building an adequate model of activity food complex under certain conditions are relevant and require further research.

\section{Formulating purpose of research}

Usually, most of the tasks related to the construct of dependencies "phenomenon-factors" in the economy and management are resolved by means of mathematical statistics and relate to the processing of numerical data arrays under a specific procedure [4]. Standard mathematical provision of personal computers allows to significantly facilitate multidimensional statistical analysis. Methodic for using standard spreadsheet functions Excel for economic analysis are detailed described in many works, in particular [5]. Received in result processing numeric date of the regression equation describes the activity of the food complex (the dependence of the food industry from raw materials base).

As a result, the purpose of the study is to build analytical dependence of the results of the food industry from the structure of production of agricultural sector based on the data of previous periods. 


\section{Stated of the main material}

The level of production of gross domestic product both in absolute terms, and in relative (per capita) is one of the important macroeconomic indicators developments of the state and region. Important additional indicators are the structure and content in it of the gross domestic product of agriculture [3]. In modern conditions dominates the concept of "food complex", which includes the agrarian sector, food and processing industry population. The level of food consumption is certainly determined by the physical and economic availability for the

In market conditions is the main is factor of economic availability of food products. However, the level production of food and food raw materials for food and processing industry is not the last role [1]. In most statistical observations production of production of agricultural sector is divided into major animal products (meat, milk, eggs) and production of agricultural crops (grain and leguminous crops, sugar beet, sunflower, potatoes, crops vegetables, fruits and berries). Following the structure, the raw material base of the Dnipropetrovsk region food industry is characterized by indicators shown in tabl. 1.

Table 1. Pointers characterizing the raw material base of the food industry

\begin{tabular}{|c|c|c|c|c|c|c|c|c|c|}
\hline \multirow[b]{3}{*}{ Year } & \multicolumn{9}{|c|}{ Raw material base } \\
\hline & \multicolumn{3}{|c|}{$\begin{array}{l}\text { Production of animal } \\
\text { products }\end{array}$} & \multicolumn{6}{|c|}{ Production of agricultural crops } \\
\hline & $\begin{array}{l}\text { meat, } \\
\text { thsd. t. }\end{array}$ & $\begin{array}{l}\text { milk, } \\
\text { thsd. t. }\end{array}$ & $\begin{array}{l}\text { eggs, } \\
\text { mln. } \\
\text { pcs. }\end{array}$ & $\begin{array}{l}\text { grain and } \\
\text { legumino } \\
\text { us crops, } \\
\text { thsd. c. }\end{array}$ & $\begin{array}{l}\text { sugar } \\
\text { beet, } \\
\text { thsd. c. }\end{array}$ & $\begin{array}{l}\text { sunflower, } \\
\text { thsd. c. }\end{array}$ & $\begin{array}{l}\text { potatoes, } \\
\text { thsd. c. }\end{array}$ & $\begin{array}{c}\text { crops vege- } \\
\text { tables, } \\
\text { thsd. c. }\end{array}$ & $\begin{array}{l}\text { fruits and } \\
\text { berries, } \\
\text { thsd. c. }\end{array}$ \\
\hline 2004 & 93,9 & 492,6 & 738,4 & 30567,9 & 4369,1 & 3587,7 & 6742 & 4986,7 & 1636,9 \\
\hline 2005 & 118,4 & 494 & 881,3 & 29083,9 & 3586,3 & 6129,2 & 5835,3 & 4939 & 1661,2 \\
\hline 2006 & 137,1 & 474,3 & 974,9 & 26352,7 & 5851,9 & 7651,3 & 5814,9 & 5251,2 & 784 \\
\hline 2007 & 159,3 & 415,7 & 879,7 & 16718,5 & 1557,9 & 6176,5 & 3788,9 & 4693,1 & 1521,2 \\
\hline 2008 & 184,8 & 381,4 & 904,1 & 36938,7 & 430,6 & 8514,4 & 5701,1 & 5411,7 & 1570,8 \\
\hline 2009 & 197,0 & 359,2 & 955,6 & 28172,3 & 385,6 & 8284,6 & 4503,2 & 5544,8 & 1079,3 \\
\hline 2010 & 207,4 & 339,8 & 998,2 & 27086,1 & 325,4 & 8555,1 & 4340,1 & 5602,8 & 1308,7 \\
\hline 2011 & 225,9 & 341,7 & 1092,8 & 34560,9 & 825,6 & 10345,1 & 5615,8 & 6740,5 & 1567 \\
\hline 2012 & 225,5 & 343,4 & 1093 & 15542,7 & 444,9 & 8029,3 & 4817,2 & 6716,4 & 1571,1 \\
\hline 2013 & 227,4 & 348 & 954,5 & 37103,4 & 382,8 & 11728,2 & 5364 & 6000,1 & 1747,9 \\
\hline 2014 & 224,5 & 357,2 & 1046,6 & 33178,4 & 285,5 & 9455 & 6589,5 & 7096,5 & 1330,7 \\
\hline 2015 & 230,0 & 344,6 & 923,7 & 38662,4 & 313,8 & 11986,5 & 5602,7 & 7283,6 & 1454,7 \\
\hline 2016 & 239,7 & 319,5 & 803,1 & 34808,1 & 541,9 & 12640,7 & 6020,9 & 7327,4 & 1494 \\
\hline 2017 & 258,0 & 300,7 & 845,3 & 35784,3 & 550,8 & 12028,1 & 5678,1 & 7026,3 & 1413 \\
\hline
\end{tabular}

Compiled on based on data [6-7]

Corresponding pointers characterizing the dynamics activate of food industry are given in tabl. 2.

As can be seen from tabl. 1 and 2, the resultant indication (production of foodstuffs, beverages and tobacco products) and factors (pointers of raw material base production) are presented in different units of measurement, which are not comparable to each other. In order to bring the pointers of production of animal products and agricultural crops into conformity with each other and with pointers of production of foodstuffs, beverages and tobacco products, it is necessary to convert them into a monetary look. 
Table 2. Pointers characterizing the activate of food industry

\begin{tabular}{|c|c|c|c|c|c|c|c|c|c|c|c|c|c|c|}
\hline Year & ঠి & $\stackrel{n}{\stackrel{2}{8}}$ & ஜ̊ & ষ্ণ & $\stackrel{\infty}{\stackrel{0}{\circ}}$ & ஓे & 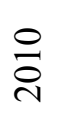 & $\overline{\check{i}}$ & $\stackrel{\sim}{\stackrel{\sim}{\sim}}$ & $\frac{m}{i}$ & $\underset{⿱ 亠}{\stackrel{\nabla}{\sim}}$ & $\stackrel{n}{\stackrel{n}{c}}$ & $\stackrel{0}{\stackrel{0}{0}}$ & $\overline{\vec{c}}$ \\
\hline $\begin{array}{l}\text { Production of foods- } \\
\text { tuffs, beverages and } \\
\text { tobacco products } \\
\text { (thsd. UAH) }\end{array}$ & 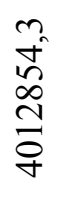 & $\begin{array}{l}0 \\
\text { do } \\
\stackrel{1}{\sigma} \\
\text { in }\end{array}$ & ญ̊ & $\begin{array}{l}v_{n} \\
\tilde{o} \\
\frac{a}{\sigma}\end{array}$ & $\begin{array}{l}\nabla_{n} \\
\stackrel{\infty}{N} \\
\underset{n}{N} \\
\sigma\end{array}$ & $\frac{\mathfrak{\Omega}}{2}$ & $\begin{array}{l}a \\
\hat{m} \\
\hat{\sigma} \\
\stackrel{n}{=}\end{array}$ & 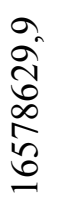 & 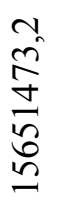 & $\begin{array}{l}2 \\
8 \\
8 \\
2 \\
n \\
n \\
n\end{array}$ & $\begin{array}{l}0 \\
\infty \\
\infty \\
+ \\
\infty \\
\infty \\
0 \\
0\end{array}$ & 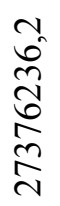 & 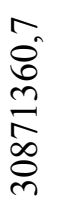 & $\begin{array}{l}\vec{\sigma} \\
\tilde{n} \\
\tilde{n} \\
\tilde{n} \\
\tilde{n}\end{array}$ \\
\hline
\end{tabular}

Compiled on based on data [8]

Bringing the pointers activate of the agricultural sector for the food complex to the unified dimension is carried out by multiplying the value of the pointer in a natural expression to the corresponding price of the unit of production (based to [9]), taking into account units of measurement (application the respective coefficients).

The results of bringing pointers characterizing the raw material base food industry of the region`s to the only monetary measurement (in thousands of UAH) are shown in tabl. 3-5.

As a result, a numeric array of data that is suitable for further statistical processing is are in tabl. 6. The resultant indicator (production of foodstuffs, beverages and tobacco products) is marked by the letter Y. Factors (Pointers of production of animal products and agricultural crops), in the order of mention, marked with the letter $\mathrm{X}$ with index from 1 to 9.

Тo perform regression analysis we will use Excel built-in function "ЛИНЕЙН".

The results of coefficients estimation for factors resultant indicator are grouped in table 7.

Table 3. Pointers characterizing the raw material base in monetary look

\begin{tabular}{|c|c|c|c|c|c|c|c|c|c|}
\hline \multirow{4}{*}{ Year } & \multicolumn{9}{|c|}{ Raw material base } \\
\hline & \multicolumn{9}{|c|}{ Production of animal products } \\
\hline & \multicolumn{3}{|c|}{ meat } & \multicolumn{3}{|c|}{ milk } & \multicolumn{3}{|c|}{ eggs } \\
\hline & thsd. t. & $\begin{array}{c}\text { UAH per } \\
\text { t. }\end{array}$ & thsd. UAH & thsd. t. & $\begin{array}{c}\text { UAH per } \\
\text { t. }\end{array}$ & thsd. UAH & mln. pcs. & $\begin{array}{l}\text { UAH per } \\
\text { thsd. pcs. }\end{array}$ & $\begin{array}{l}\text { thsd. } \\
\text { UAH }\end{array}$ \\
\hline 2004 & 93,9 & 4489,4 & 421554,7 & 492,6 & 952,5 & 469201,5 & 738,4 & 224,5 & 165770,8 \\
\hline 2005 & 118,4 & 7002,3 & 829072,3 & 494 & 1253 & 618982,0 & 881,3 & 261,3 & 230283,7 \\
\hline 2006 & 137,1 & 6294,6 & 862989,7 & 474,3 & 1187,4 & 563183,8 & 974,9 & 183,2 & 178601,7 \\
\hline 2007 & 159,3 & 6576,6 & 1047652,4 & 415,7 & 1734,2 & 720906,9 & 879,7 & 257 & 226082,9 \\
\hline 2008 & 184,8 & 10457,5 & 1932546,0 & 381,4 & 2332,2 & 889501,1 & 904,1 & 385,7 & 348711,4 \\
\hline 2009 & 197,0 & 10769,7 & 2121630,9 & 359,2 & 2068,3 & 742933,4 & 955,6 & 402,4 & 384533,4 \\
\hline 2010 & 207,4 & 10826,5 & 2245416,1 & 339,8 & 3195,6 & 1085864,9 & 998,2 & 452,4 & 451585,7 \\
\hline 2011 & 225,9 & 11850,3 & 2676982,8 & 341,7 & 3165 & 1081480,5 & 1092,8 & 493,2 & 538969,0 \\
\hline 2012 & 225,5 & 13715,9 & 3092935,5 & 343,4 & 2867,1 & 984562,1 & 1093 & 587,1 & 641700,3 \\
\hline 2013 & 227,4 & 12976,2 & 2950787,9 & 348 & 3563,5 & 1240098,0 & 954,5 & 621,7 & 593412,7 \\
\hline 2014 & 224,5 & 15635,8 & 3510237,1 & 357,2 & 3796,2 & 1356002,6 & 1046,6 & 740,6 & 775112,0 \\
\hline 2015 & 230,0 & 20356,9 & 4682087,0 & 344,6 & 4402,4 & 1517067,0 & 923,7 & 1070 & 988359,0 \\
\hline 2016 & 239,7 & 22851,3 & 5477456,6 & 319,5 & 5470 & 1747665,0 & 803,1 & 1021,2 & 820125,7 \\
\hline 2017 & 258,0 & 30036,0 & 7749288,0 & 300,7 & 7517,3 & 2260452,1 & 845,3 & 1049,4 & 887057,8 \\
\hline
\end{tabular}


Table 4. Pointers characterizing the raw material base in monetary look

\begin{tabular}{|r|r|r|r|r|r|r|r|r|r|}
\hline \multirow{2}{*}{ Year } & \multicolumn{70}{|c|}{ Raw material base } \\
\cline { 2 - 11 } & \multicolumn{7}{|c|}{ Production of agricultural crops } \\
\cline { 2 - 11 } & grain and leguminous crops & \multicolumn{3}{|c|}{ sugar beet } & \multicolumn{3}{|c|}{ sunflower } \\
\cline { 2 - 11 } & thsd. c. & $\begin{array}{l}\text { UAH } \\
\text { per t. }\end{array}$ & thsd. UAH & thsd. c. & $\begin{array}{l}\text { UAH } \\
\text { per t. }\end{array}$ & \multicolumn{1}{c|}{$\begin{array}{l}\text { thsd. } \\
\text { UAH }\end{array}$} & thsd. c. & $\begin{array}{l}\text { UAH } \\
\text { per t. }\end{array}$ & thsd. UAH \\
\hline 2004 & 30567,9 & 434,3 & 1327563,9 & 4369,1 & 132,8 & 58021,6 & 3587,7 & 1162,6 & 417106,0 \\
\hline 2005 & 29083,9 & 402,6 & 1170917,8 & 3586,3 & 164,1 & 58851,2 & 6129,2 & 1012,2 & 620397,6 \\
\hline 2006 & 26352,7 & 501,5 & 1321587,9 & 5851,9 & 184,5 & 107967,6 & 7651,3 & 960,1 & 734601,3 \\
\hline 2007 & 16718,5 & 802,7 & 1341994,0 & 1557,9 & 158,1 & 24630,4 & 6176,5 & 1820,3 & 1124308,3 \\
\hline 2008 & 36938,7 & 728,8 & 2692092,5 & 430,6 & 184,3 & 7936,0 & 8514,4 & 1534,5 & 1306534,7 \\
\hline 2009 & 28172,3 & 758,8 & 2137714,1 & 385,6 & 476,3 & 18366,1 & 8284,6 & 1934,9 & 1602987,3 \\
\hline 2010 & 27086,1 & 1039,5 & 2815600,1 & 325,4 & 330,2 & 10744,7 & 8555,1 & 2950,9 & 2524524,5 \\
\hline 2011 & 34560,9 & 1327,2 & 4586922,6 & 825,6 & 413,7 & 34155,1 & 10345,1 & 3275,2 & 3388227,2 \\
\hline 2012 & 15542,7 & 1562 & 2427769,7 & 444,9 & 371,7 & 16536,9 & 8029,3 & 3594 & 2885730,4 \\
\hline 2013 & 37103,4 & 1279,9 & 4748864,2 & 382,8 & 430,4 & 16475,7 & 11728,2 & 2971,6 & 3485151,9 \\
\hline 2014 & 33178,4 & 1828,2 & 6065675,1 & 285,5 & 492,8 & 14069,4 & 9455 & 3920,2 & 3706549,1 \\
\hline 2015 & 38662,4 & 2733,5 & 10568367,0 & 313,8 & 672,9 & 21115,6 & 11986,5 & 7413,9 & 8886671,2 \\
\hline 2016 & 34808,1 & 3317,3 & 11546891,0 & 541,9 & 803,6 & 43547,1 & 12640,7 & 8462,4 & 10697066,0 \\
\hline 2017 & 35784,3 & 3733,8 & 13361141,9 & 550,8 & 941,4 & 51852,3 & 12028,1 & 8874,5 & 10674337,3 \\
\hline Compiled on based on data [6-9] & & & & & & \\
\hline
\end{tabular}

Table 5. Pointers characterizing the raw material base in monetary look

\begin{tabular}{|c|c|c|c|c|c|c|c|c|c|}
\hline \multirow{4}{*}{ Year } & \multicolumn{9}{|c|}{ Raw material base } \\
\hline & \multicolumn{9}{|c|}{ Production of agricultural crops } \\
\hline & \multicolumn{3}{|c|}{ potatoes } & \multicolumn{3}{|c|}{ crops vegetables } & \multicolumn{3}{|c|}{ fruits and berries } \\
\hline & thsd. c. & $\begin{array}{c}\text { UAH per } \\
\text { t. }\end{array}$ & thsd. UAH & thsd. c. & $\begin{array}{c}\text { UAH per } \\
\text { t. }\end{array}$ & $\begin{array}{l}\text { thsd. } \\
\text { UAH }\end{array}$ & thsd. c. & $\begin{array}{c}\text { UAH per } \\
\text { t. }\end{array}$ & thsd. UAH \\
\hline 2004 & 6742 & 531,2 & 358135,0 & 4986,7 & 1658,6 & 827094,1 & 1636,9 & 1369,9 & 224238,9 \\
\hline 2005 & 5835,3 & 654 & 381628,6 & 4939 & 2355,2 & 1163233,3 & 1661,2 & 1503,2 & 249711,6 \\
\hline 2006 & 5814,9 & 1404,5 & 816702,7 & 5251,2 & 2536 & 1331704,3 & 784 & 2395,6 & 187815,0 \\
\hline 2007 & 3788,9 & 1111,7 & 421212,0 & 4693,1 & 2832,9 & 1329508,3 & 1521,2 & 1407,8 & 214154,5 \\
\hline 2008 & 5701,1 & 1294,6 & 738064,4 & 5411,7 & 3477,8 & 1882081,0 & 1570,8 & 3190,9 & 501226,6 \\
\hline 2009 & 4503,2 & 1826,8 & 822644,6 & 5544,8 & 3088,4 & 1712456,0 & 1079,3 & 3812,6 & 411493,9 \\
\hline 2010 & 4340,1 & 2330,7 & 1011547,1 & 5602,8 & 4069,8 & 2280227,5 & 1308,7 & 3428,2 & 448648,5 \\
\hline 2011 & 5615,8 & 2545,1 & 1429277,3 & 6740,5 & 2817,5 & 1899135,9 & 1567 & 4250,2 & 666006,3 \\
\hline 2012 & 4817,2 & 1256,3 & 605184,8 & 6716,4 & 2771,7 & 1861584,6 & 1571,1 & 4796,1 & 753515,3 \\
\hline 2013 & 5364 & 2321 & 1244984,4 & 6000,1 & 2948,6 & 1769189,5 & 1747,9 & 5115,2 & 894085,8 \\
\hline 2014 & 6589,5 & 3408,1 & 2245767,5 & 7096,5 & 3482,6 & 2471427,1 & 1330,7 & 6003 & 798819,2 \\
\hline 2015 & 5602,7 & 3330,9 & 1866203,3 & 7283,6 & 5894,4 & 4293245,2 & 1454,7 & 6651,4 & 967579,2 \\
\hline 2016 & 6020,9 & 2864,1 & 1724446,0 & 7327,4 & 6002,2 & 4398052,0 & 1494 & 6886,6 & 1028858,0 \\
\hline 2017 & 5678,1 & 3788,2 & 2150977,8 & 7026,3 & 6602,1 & 4638833,5 & 1413 & 7984,7 & 1128238,1 \\
\hline
\end{tabular}


Table 6. Numeric array of data

\begin{tabular}{|r|c|c|c|c|c|c|c|c|c|c|}
\hline & $\mathrm{X} 1$ & $\mathrm{X} 2$ & $\mathrm{X} 3$ & $\mathrm{X} 4$ & $\mathrm{X} 5$ & $\mathrm{X} 6$ & $\mathrm{X} 7$ & $\mathrm{X} 8$ & $\mathrm{X} 9$ & $\mathrm{Y}$ \\
\hline 1 & 421554,7 & 469201,5 & 165770,8 & 1327563,9 & 58021,6 & 417106,0 & 358135,0 & 827094,1 & 224238,9 & 4012854,3 \\
\hline 2 & 829072,3 & 618982,0 & 230283,7 & 1170917,8 & 58851,2 & 620397,6 & 381628,6 & 1163233,3 & 249711,6 & 5461162,0 \\
\hline 3 & 862989,7 & 563183,8 & 178601,7 & 1321587,9 & 107967,6 & 734601,3 & 816702,7 & 1331704,3 & 187815,0 & 6210002,6 \\
\hline 4 & 1047652,4 & 720906,9 & 226082,9 & 1341994,0 & 24630,4 & 1124308,3 & $421212,01329508,3$ & 214154,5 & 6991055,4 \\
\hline 5 & 1932546,0 & 889501,1 & 348711,4 & 2692092,5 & 7936,0 & 1306534,7 & $738064,41882081,0$ & 501226,6 & 9321787,4 \\
\hline 6 & 2121630,9 & 742933,4 & 384533,4 & 2137714,1 & 18366,1 & 1602987,3 & $822644,61712456,0$ & 411493,9 & 9971925,9 \\
\hline 7 & 2245416,1 & 1085864,9 & 451585,7 & 2815600,1 & 10744,7 & 2524524,5 & $1011547,12280227,5$ & 448648,5 & 11565139,9 \\
\hline 8 & 2676982,8 & 1081480,5 & 538969,0 & 4586922,6 & 34155,1 & 3388227,2 & 1429277,3 & 1899135,9 & 666006,3 & 16578629,9 \\
\hline 9 & 3092935,5 & 984562,1 & 641700,3 & 2427769,7 & 16536,9 & 2885730,4 & 605184,8 & 1861584,6 & 753515,3 & 15651473,2 \\
\hline 10 & 2950787,9 & 1240098,0 & 593412,7 & 4748864,2 & 16475,7 & 3485151,9 & $1244984,41769189,5$ & 894085,8 & 15955960,2 \\
\hline 11 & 3510237,1 & 1356002,6 & 775112,0 & 6065675,1 & 14069,4 & 3706549,1 & $2245767,52471427,1$ & 798819,2 & 19688448,6 \\
\hline 12 & 4682087,0 & 1517067,0 & 988359,0 & 10568367,0 & 21115,6 & 8886671,2 & $1866203,34293245,2$ & 967579,2 & 27376236,2 \\
\hline 13 & 5477456,6 & 1747665,0 & 820125,7 & 11546891,0 & 43547,1 & 10697066,0 & $1724446,04398052,0$ & $1028858,030871360,7$ \\
\hline 14 & 7749288,0 & 2260452,1 & 887057,8 & 13361141,9 & 51852,3 & 10674337,3 & $2150977,84638833,5$ & 1128238,1 & 32383313,4 \\
\hline
\end{tabular}

Table 7. The results of coefficients estimation

\begin{tabular}{|c|c|c|c|c|}
\hline \multicolumn{2}{|r|}{ Factor } & \multicolumn{2}{|c|}{ Coefficient } & \multirow{2}{*}{$\begin{array}{c}\text { Standard val- } \\
\text { ue errors }\end{array}$} \\
\hline marked & name & marked & value & \\
\hline $\mathrm{X} 1$ & meat & $\mathrm{k} 1$ & 1,275852 & 0,781221 \\
\hline $\mathrm{X} 2$ & milk & $\mathrm{k} 2$ & $-2,27146$ & 3,494836 \\
\hline $\mathrm{X} 3$ & eggs & $\mathrm{k} 3$ & 2,773841 & 5,172413 \\
\hline $\mathrm{X} 4$ & grain and leguminous crops & $\mathrm{k} 4$ & $-0,87669$ & 0,529605 \\
\hline $\mathrm{X} 5$ & sugar beet & $\mathrm{k} 5$ & $-6,91482$ & 14,30335 \\
\hline $\mathrm{X} 6$ & sunflower & $\mathrm{k} 6$ & 2,409149 & 0,646382 \\
\hline $\mathrm{X} 7$ & potatoes & $\mathrm{k} 7$ & 3,403518 & 1,374676 \\
\hline $\mathrm{X} 8$ & crops vegetables & $\mathrm{k} 8$ & $-0,79708167$ & 1,298809493 \\
\hline $\mathrm{X} 9$ & fruits and berries & $\mathrm{k} 9$ & 3,890614704 & 4,12816942 \\
\hline & Free member & $\mathrm{b}$ & 3618226 & 2567507 \\
\hline
\end{tabular}

That is, received the regression model of the dependence of the volume of production of foodstuffs, beverages and tobacco products from volumes of production of animal products and agricultural crops is as follows:

$$
\begin{aligned}
& \mathrm{Y}=1,275852 * \mathrm{X} 1-2,27146 * \mathrm{X} 2+2,773841 * \mathrm{X} 3-0,87669 * \mathrm{X} 4-6,91482 * \mathrm{X} 5+ \\
& +2,409149 * \mathrm{X} 6+3,403518 * \mathrm{X} 7-0,79708167 * \mathrm{X} 8+3,890614704 * \mathrm{X} 9+3618226 .
\end{aligned}
$$

Conclusions and prospects for further research

The standard errors values for the coefficients are within allowable limits (special attention should be paid to the estimation of factor X5 - production of sugar beet). The coefficient of determinants is close to $1(0.997648473)$, which indicates a sufficiently full correlation of the model with data [10]. The standard error for assessing the resultant indicator is 824 thousand. UAH. Deviation of the settlement value of the volume of production of foodstuffs, beverages and tobacco products from the actual amounted to 104743.7 thousand. UAH. or 0.32345 percent. All this indicates the adequacy of the obtained model and the possibility of its further use for the purpose of forecasting or assessing the degree of influence of factors. 
From the resulting equation can be seen that the factors X1-production of meat, X3production of egg, X6-production of sunflower, X7-production of potatoes, X9-production of fruit and berry crops positively affects in the volume of food products. At the same time, the dynamics of factors X2-production of milk, X4-production of grain and leguminous crops, X5-production of sugar beet and X8 -production of crops vegetable generates a negative trend.

Further investigations can be connected both with refine data (refine your model, taking into account additional factors) and using the obtained model for the purposes of forecasting and programming of food industry in the region.

\section{References}

[1] Koreniuk, P.I. (2009). Эffektyvnost yspolzovanyia y vosproyzvodstva pryrodno-resursnoho potentsyala: fynansovbie faktori, domynyruiushchye tendentsyy [Efficiency of use and reproduction of natural resource potential: financial factors, dominant tendencies]. Dnepropetrovsk: DDFA [in Ukrainian].

[2] Deineko, L.V. (2008). Rozvytok kharchovoi promyslovosti v umovakh rynkovykh peretvoren: problemy teorii i praktyky [The development of the food industry in the context of market transformations: problems of theory and practice]. Kyiv: Znannia [in Ukrainian].

[3] Tracy M. (1995). Selskoe khoziaistvo y prodovolstvye v эkonomyke razvytalkh stran [Agriculture and food in the economy of developed countries]. (A. Sutskyi, Trans). Saint Petersburg: Эkonomycheskaia shkola [in Russian].

[4] Eddowes, M. \& Stansfield, R. (1997). Metodi pryniatyia reshenyi [Methods of decision making]. (Trans). Moscow: UNITI [in Russian].

[5] Avramenko, V. I. \& Karimov, I. K. (2013). Teoriia ymovirnostei i matematychna statystyka [Theory of chances and mathematical statistics]. (2nd ed., rev.).Dniprodzerzhynsk: DDTU [in Ukrainian].

[6] Holovne upravlinnia statystyky u Dnipropetrovskii oblasti. Ofitsiinyi veb-sait. Statystychna informatsiia. Silske, lisove ta rybne hospodarstvo. Roslynnytstvo (1995-2018 roky) [Main administration of statistics is in the Dnipropetrovsk region. Official web site. Statistical information. Agriculture, forestry and fisheries. Crop production (1995-2018)]. dneprstat.gov. ua/statinfo\% 202015 /sg /2018/sg6.pdf Retrieved from http://dneprstat.gov. ua/statinfo\% 202015 /sg /2018/sg6.pdf [in Ukrainian].

[7] Holovne upravlinnia statystyky u Dnipropetrovskii oblasti. Ofitsiinyi veb-sait. Statystychna informatsiia. Silske, lisove ta rybne hospodarstvo. Tvarynnytstvo (1995-2018 rr) [Main administration of statistics is in the Dnipropetrovsk region. Official web site. Statistical information. Agriculture, forestry and fisheries. Livestock breeding (1995-2018)]. dneprstat.gov. ua/statinfo\% 202015 /sg /2018/sg7-8.pdf Retrieved from http://dneprstat.gov. ua/statinfo\% 202015 /sg 12018/sg7-8.pdf [in Ukrainian].

[8] Holovne upravlinnia statystyky u Dnipropetrovskii oblasti. Ofitsiinyi veb-sait. Statystychna informatsiia. Promyslovist. Obsiah realizovanoi promyslovoi produktsii (tovariv, posluh) za vydamy ekonomichnoi diialnosti [Main administration of statistics is in the Dnipropetrovsk region. Official web site. Statistical information. Industry. Volume of sold industrial products (goods, services) by types of economic activity]. dneprstat.gov. ua/statinfo\% $202015 / p / 2018 / p 14 . p d f$ Retrieved from http://dneprstat.gov. ua/statinfo\% 202015 /p /2018/p14.pdf [in Ukrainian].

[9] Holovne upravlinnia statystyky u Dnipropetrovskii oblasti. Ofitsiinyi veb-sait. Statystychna informatsiia. Silske, lisove ta rybne hospodarstvo. Seredni tsiny produktsii silskoho hospodarstva, realizovanoi pidpryiemstvamy (1996-2018 rr) [Main administration of statistics is in the Dnipropetrovsk region. Official web site. Statistical information. Agriculture, forestry and fisheries. Average prices of agricultural products sold by enterprises (1996-2018)]. dneprstat.gov. ua/statinfo\% 202015 /sg /2019/sg10.pdf Retrieved from http://dneprstat.gov. ua/statinfo\% $202015 /$ sg /2019/sg10.pdf [in Ukrainian].

[10] Taha, Hamdy A. (2001). Vvedenye v yssledovanye operatsyi [Operations research an introduction]. (6nd ed., rev.). (Trans). Moscow: Yzdatelskyi dom "Vyliams" [in Russian]. 


\title{
МОДЕЛЮВАННЯ ЗАЛЕЖНОСТІ ХАРЧОВОЇ ПРОМИСЛОВОСТІ ВІД СИРОВИННОЇ БАЗИ
}

\author{
Карімов Г.І., Звонарьова К.А.
}

В сучасних умовах перебудови промислових галузей економіки України та їі регіонів, значно посилюється орієнтація їх діяльності на всебічне і повне задоволення потреб населення в товарах народного споживання, в першу чергу в недорогих і високоякісних харчових продуктах. Тому, пріоритетною стає проблема ефективного функціонування і подальшого розвитку харчової промисловості, їі галузей та виробництв. Проблема ефективного функціонування і розвитку харчової промисловості тісно пов'язана із діяльністю аграрного сектору продовольчого комплексу регіону, оскільки його продукція є сировинною базою для підприємств харчової та переробної галузі. Незважаючи на достатньо повний опис проблеми вітчизняними та зарубіжними вченими, питання побудови адекватної моделі діяльності продовольчого комплексу в певних умовах, є актуальними та потребують подальших досліджень.

Мета дослідження - побудова аналітичної залежності результатів діяльності харчової промисловості від структури випуску продукції аграрного сектору на основі даних минулих періодів.

В загальному випадку виробництво продукції аграрного сектору поділяють на продукцію тваринництва (м'ясо, молоко, яйця) та виробництво сільськогосподарських культур (культури зернові та зернобобові, буряк цукровий, соняшник, картопля, культури овочеві, культури плодові та ягідні). Дана структура випуску продукції сировинної бази харчової промисловості Дніпропетровської області за 2004-2017 роки врахована чинниками, що впливають на значення обсягу виробництва харчових продуктів, напоїв і тютюнових виробів. Натуральні показники переведено у вартісні з урахуванням єдиної одиниці виміру — тисячі гривень.

В отриманій регресійній моделі стандартні значення помилок коефіцієнтів знаходяться у допустимих межах. Але слід звернути увагу на оцінку п’ятого чинника — виробництво буряка цукрового. Коефіцієнт детермінованості склав 0,998, що вказує на достатньо повну кореляцію моделі. Відхилення розрахункового значення обсягу виробництва харчової промисловості від фактичного склало 104743,7 тис. грн. або 0,32 відсотки. Можливо зробити висновок про адекватність отриманої моделі та можливість іiі подальшого використання для цілей прогнозування або оцінки ступеню впливу чинників.

Подальші дослідження можуть бути пов’язані з уточненням моделі, врахуванням додаткових факторів, використанням отриманої моделі для цілей прогнозування та програмування розвитку харчової промисловості регіону.

\section{Лiтература}

1. Коренюк П.И. Эффективность использования и воспроизводства природно-ресурсного потенциала: финансовые факторы, доминирующие тенденции: монография. Днепропетровск: ДДФА, 2009. 120 с.

2. Дейнеко Л.В. Розвиток харчової промисловості в умовах ринкових перетворень: проблеми теорії і практики. монографія. Київ: Знання, 1999.331 с.

3. Трейси М. Сельское хозяйство и продовольствие в экономике развитых стран / ред. А.Г. Суцкий; пер. с англ. Санкт-Петербург: Экономическая школа, 1995. 431 с.

4. Эддоус М., Стенсфилд Р. Методы принятия решений. / пер. с англ. Москва: ЮНИТИ, $1997.590 \mathrm{c}$.

5. Авраменко В.І., Карімов І. К. Теорія ймовірностей і математична статистика: навч. посібник. Вид.2-ге, перероб. і доп. / Дніпровський держ. тех.ун-т. Дніпродзержинськ : ДДТУ, 2013. 247 с.

6. Рослинництво (1995-2018 роки) (за даними головного управління статистики у Дніпропетровській області). URL: http://dneprstat.gov. ua/statinfo\% 202015 /sg /2018/sg6.pdf (дата звернення: 19.03.2019). 
7. Тваринництво (1995-2018pр.) (за даними головного управління статистики у Дніпропетровській області). URL: http://dneprstat.gov.ua/statinfo\%202015/sg/2018/sg7-8.pdf (дата звернення: 19.03.2019).

8. Обсяг реалізованої промислової продукції (товарів, послуг) за видами економічної діяльності (за даними головного управління статистики у Дніпропетровській області). URL: http://dneprstat.gov.ua/statinfo\%202015/p/2018/p14.pdf (дата звернення: 19.03.2019).

9. Середні ціни продукції сільського господарства, реалізованої підприємствами (19962018pp.) (за даними головного управління статистики у Дніпропетровській області). URL: http://dneprstat.gov.ua/statinfo\%202015/sg/2019/sg10.pdf (дата звернення: 19.03.2019).

10. Таха Хемди А. Введение в исследование операций. Изд. 6-е / пер. с англ. Москва: Издательский дом "Вильямс", 2001. 912 с. 